\title{
Analyzing Assessment Questions in an Arabic Textbook (Communication Skills) for Eight Grade in Jordan According to Bloom's Taxonomy of Levels of Knowledge Aims
}

\author{
Hasan AbdRabbeh Ali Al-hasanat ${ }^{1, *}$ \\ ${ }^{1}$ Curriculum and Instruction of Arabic Language, School of Education, Al-Hussein Bin Talal University, P.O. Box \\ (20), Ma'an, Jordan \\ *Correspondence: Curriculum and Instruction of Arabic Language, School of Education, Al-Hussein Bin Talal \\ University, P.O. Box (20), Ma'an, Jordan. E-mail: hasanhasanat@yahoo.com
}

Received: March 3, 2016

Accepted: March 10, 2016 Online Published: April 18, 2016

doi:10.5430/wje.v6n2p68

URL: http://dx.doi.org/10.5430/wje.v6n2p68

\begin{abstract}
This study aims at analyzing assessment questions included in an Arabic language textbook (Communication Skills) for eight grade in the Jordanian schools according to the levels of knowledge in Bloom's Taxonomy to reveal the percentages of distributing of these questions against this taxonomy. In order to achieve the purposes of this study, the researcher designed the instrument of analysis which he applied to the 520 questions included in the textbook for both first and second semesters.

Data was identified, recorded and the results were compared to the standard percentages identified by using the means introduced by the specialists. The results of this study revealed that the textbook questions mostly focused on the lower levels of thinking. Results also showed a graphic disagreement between the percentages of the distribution of the textbook assessment questions and the standard percentages at five levels (Remembering, Understanding and Comprehension, Application, Analysis and Evaluation). In the light of these results, the research recommends that there should be a stronger focus on questions of higher levels of thinking in an Arabic Language textbook for grade eight particularly at the levels of application, analysis and evaluation. It also recommends a gradual increase of balanced questions in any future textbook production, and more content analysis studies should include Arabic language textbooks at all stages.
\end{abstract}

Keywords: assessment questions; communication skills; bloom's taxonomy

\section{Introduction}

One of the best ways to teach and learn the Arabic language is through a school curricula by which the general goals of education can be achieved. These goals include creating the good citizen who should be provided with scientific and objective thinking and who considers science as his or her reference in solving both personal and social problems. Being the major tool in the learning or teaching process, school textbooks received the attention of teachers, parents and students through ages (AL-Samook \& AL-Shammari, 2009). Marei and Al Heilah (2003) emphasized the importance of designing and producing school textbooks with a content that meets the scientific and educational standards because content is one of the major components of any educational curricula.

Though the textbook occupies a basic position in the learning process, the efforts of the educators concentrated on both the developing of the textbooks and the continuous evaluation of the content of the book.

Questions, exercises and activities are considered as one of the textbook content components. Therefore, we find that many studies recommend interesting in question technique which allows creating perception of learners at the age of higher primary stage. Skaker (1995) argued that in order to achieve this better level of thinking, students should be asked questions that go beyond than just knowing facts. This supports the conclusions made by Bloom and his assistant who stated that a certain type of questions leads to a certain type of thinking (Bloom et al, 1989).

Many Jordanian studies revealed an alarming level of weakness among students in all Arabic language learning skills. According to the students, this weakness is due to a variety of reasons. Ironically, school textbooks that were 
intended to eliminate this weakness do actually play a significant role in causing it (Migdadi, 1992; Al-Haj Eisa, 1995; Ministry of Education, 2000-2003).

On the contrary, there are many studies which indicated to the necessity of using the question requesting higher mental abilities in the textbooks which may result in increasing the ability of the students to get better results. This study will deal with other Arab and foreign studies.

Questions that evoke higher levels of thinking that involve analysis, creativity and evaluation utilize students giving opinions in order to make decisions and to suggest solutions to certain problems. This kind of learning provides more opportunities for students to think individually. However, this tendency toward emphasizing higher levels of thinking does not recommend ignoring other levels of thinking as they still make the connection among all levels of thinking (Sweedan, 2009).

It is worth mentioning here that some textbooks' authors and teachers in general lack the skill of building assessment questions that stimulate the different levels of thinking. Hence, the researcher finds it important that all school textbooks including Arabic language book "Communication Skills" for grade eight should provide this type of questions. This signifies the importance of analyzing evaluation activities in all Arabic language school books to investigate whether they include assessment questions that match Bloom's hierarchy.

\section{The Problem of the Study}

It seems that questions, evaluation activities and drills that school textbooks provide can be an integral part of the learning and teaching processes. Some teachers can also create and build their own assessment activities in order to check whether their students understand and are able to master any specific skill.

Many researchers examined the evaluation questions included in school textbooks in general and Arabic language textbooks in particular and found out that most of these questions are categorized as lower levels of thinking, remembering and understanding (Al-Marzouq, 1997; Al-Hwaimil, 2003; and Al-Darab'eh 2006).

These findings supported the researcher's own conclusions that he made during his teaching career in the Jordanian Ministry of Education. As a result, he decided to analyze the evaluation questions included in the "Communication Skills" Arabic language textbook for grade eight in Jordan to get a more precise assessment of these questions in comparison to Bloom's Taxonomy. The problem of the study can be stated in the following question: What levels of Bloom's Taxonomy do evaluation questions in grade eight "Communication Skills "textbook represent?

\section{The Aims of the Study}

This study aims to:

1-Categorize the evaluation questions within each of the six levels of knowledge in Boom's Taxonomy in the Arabic language textbook for grade eight in Jordan.

2- Identify what the standard percentages of the questions should be included in this textbook as suggested by experts.

3- Identify the level of agreement between the results identified by the researcher and those suggested by other researchers.

\section{The Importance of the Study}

The importance of the study can be shown as follows:

1) Questions are one of the main elements in the school textbooks and generally in teaching process. Their analysis and classification may discover important sides of teaching process system and its results.

2) The mentioned questions in the school textbooks are considered as organized methods to determine student achievement and to improve and update these questions may gain special importance mainly in the recent scientific and technological development.

3) The necessity for verification of the questions of the Arabic language "Commutation Skills" for the eighth basic class in Jordan concerning all thinking levels not only the low level but also the highest one and which fits the nature of the Arabic language. 
4) Taking into consideration the importance of verification of the questions mentioned in the textbook of the cognitive levels in balance and to achieve integration and interdependence among themselves.

5) The intended balance here doesn't mean that the cognitive levels should be in one level but it means that the questions should take into consideration those levels according to what the school stage requires for the mentioned class.

6) No studies about classifying the questions of Arabic textbook " Communication Skills " for the eighth basic class in Jordan for Bloom's cognitive levels according to the researcher.

7) The possibility of getting benefit from the authors of the curricula of the Arabic language for the basic stage in Jordan, and how to get benefit of improving and developing the questions of Arabic textbook.

\section{Research Questions}

The problem of the research can be determined by the following questions:

1) What percentage of questions contained in each level of cognitive domain levels at Bloom's Taxonomy (remembering, understanding and comprehension, application, analysis, synthesis and evaluation) in the Arabic textbook "Communication Skills" for the eighth basic class in Jordan?

2) What are the percentages of the normative questions implied in each level of the cognitive levels existing in the mentioned book?

3) What is the compatibility between the results of the analysis of the questions implied for each level of cognitive domain levels and the normative ratios mentioned in the above book?

\section{The Cortical Background}

\subsection{Evaluation in the Textbook}

AL-Samook and AL-Shammari (2009) identified the school textbook as a holistic system that includes aims, activities, aids and evaluation in addition to content. All these components are designated to help teachers teaching students a certain subject in a certain class and in order to achieve the aims introduced in a specific curriculum.

It can be said that whatever we research, the textbook still keeps its noble position (Marie \& AL-Heilah, 2000) because this textbook keeps a special position in curriculum in general as it has a basic role particularly in the process of teaching and learning (AL-Hasan \& AL-Qaid, 1999).In fact, a textbook is an educational document that reflects content, activities and assessment questions that aim at achieving the intended goals.

Taking into account that evaluation is a major aspect in school books' maps, AL-Zubi and colleagues (2007) pointed out that any evaluation process should be comprehensive and involves a variety of strategies and instruments that ensure the ability to measure the mastery of knowledge and skills. To guarantee that evaluation is a continual and a constructive process, textbooks must include assessment activities at the end of each unit that measure all the different aspects and abilities including creativity.

Darwazeh (2006) indicated that evaluating school books to making certain decisions about their importance as an educational instrument whose quality and appropriateness should reflect new trends in education. Evaluation also leads to reformation, interpretation and appreciation and it provides teachers, administrators and designers of school curriculum with necessary knowledge about the value and efficiency of curricula.

\subsection{Questions}

In educational contexts, a question has been defined in many ways:

- A question mark sentence requires a response and can be expressed by a clear and direct language which is easy for the students to understand and to be suitable with their ages and their interests and abilities (Shabatat et al, 2003).

- Every statement that requires students to answer in a manner that achieves a certain educational objective (AL-Shammari \& AL-Samouk, 2005).

It is assumed that evaluation questions are the valid outcome that appears within a certain educational context that aims at gathering necessary qualitative and quantitative information to make some judgment in the light of previously determined goals and criteria (Al-Khawaldeh \& Eid, 2003). 


\subsection{The Importance of Questions}

New trends in education emphasized the importance of questions in measuring students' achievement and diagnosing all aspects of strength and weakness. Consequently, it became as equally important to build evaluation questions that cover the different levels of knowledge and skills in the different domains (Hamadin , 2003) .

The question is a necessary requirement for the process of learning and teaching where it is an important part of the educational content to be carried out and processed through the teaching of the educational material (AL-Maliki, 2005).

AL-Zahrani (2003) addresses the role of questions in stimulating creative thinking. However, this can be achieved only by using techniques where the quality of questions is so good that they lead to a more insightful thinking.

In addition to evaluating learner's achievement including reciting and understanding content, they are so helpful in determining their readiness to learn and develop their critical thinking abilities (Lippse \& Freeman, 2004).

Darwazeh (2005) suggests that to decide that a certain question is a good question we need to measure it against several criteria. For example, whether it deals with varied intellectual processes, and whether it challenges thinking at the higher levels.

Although educators acknowledged the importance of using questions in educational contexts, they still disagree about the levels and categories of these questions. However, they are aware that learning different types of questions is a basic skill that learners should master in order to respond efficiently and positively to the different types of questions as each level of a question requires a certain level of thinking. Consequently, teachers need to be able to construct their questions from the very simple to the very sophisticated (Abdel Razaq, 2003).

The importance of assessment questions included in school textbooks can be most graphically noticed in their ability to develop critical and creative thinking among learners. They are also like teachers that can be employed to improve interactive experiences between learners and information textbooks (AL-Rawadieh, 2000).

Jasim (2000) adds that the importance of school books' assessment questions resides in that students spend a long time dealing with them for more training, and to be prepared for similar examples in their exams. In general, textbook questions affect three main domains: cognitive processes, students' attitudes and achievement.

\subsection{Bloom's Cognitive Processes}

Experts suggested a variety of taxonomies which instructional and assessment questions should be measured. However, Bloom suggested a taxonomy of cognitive processes that addresses the importance of verifying thinking skills in learners, and contributes in directing teachers' efforts during any classroom activity (Bloom et al, 1985).

There is a common agreement that this is still the best taxonomy that suits all different teaching subjects. Bloom (1964) categorized cognitive objectives into three levels: the concrete, the conceptual and the creative which requires higher intellectual skills. Learning objectives in this taxonomy go in a hierarchy where knowledge occupies its widest base and where levels proceed to evaluation representing the highest intellectual skill (Qatami; Abu Jaber and Qatami, 2002). The cognitive levels in Bloom's Taxonomy are arranged in the following order according to their importance:

1) Knowledge: This is where students are required to identify and recall information and where they focus on remembering facts that concern a branch of some field of knowledge: its terms, principles and generalization. Here, knowledge becomes the supreme goal that represents the ultimate outcome of learning and builds the platform of other educational objectives (Al-Adwan \& Al-Hawamdeh, 2008). According to Cooper (1999), the only task students should do is to recall facts and knowledge they had recited before which is a job that does not involve any level of creativity. As a result, teachers use direct questions that require neither application nor analysis to evaluate their students.

2) Understanding and Comprehension: This is the level where the learner proves that he has enough understanding that enables him to intellectually organize the content. That is, re-phrasing content in his own words (Al-Adwan \& Al-Hawamdeh, 2008). In fact, this level indicates that the learner understands the content and is able to, briefly, explain ideas. Skills within this level enable learners to merge new information with previous experiences in order to give correct answers with his own language which, in turn, requires a higher level of intellectual activity (Cooper, 1999).

3) Application: Application is where the objectives are represented by using symbolic cognition and the learner demonstrates an ability to use previously mastered knowledge in new situations (Al-Qalla , 2000). Application 
indicates the level to which the learner employs knowledge and information in novel situations and in solving new problems. This involves two steps: introducing a new problem which learners have not encountered before, and then providing the opportunity of choosing and applying a solution they know (Touq; Qatami, \& Adas, 2003).

4) Analysis: Analysis involves establishing relations in order to infer the hidden meanings in the content. Analyzing the content into its elements and then exploring the relations that organizes them prepares students to answer questions that require more insightful thinking (AL-Husari,1995).To evaluate analysis, teachers should use questions that stimulate free and effective discussions and purposive debate. This kind of analysis that helps learners distinguish between facts and opinions and discriminate between ideas is called critical thinking (Al-Fatlawi, 2003).

5) Synthesis: This is the exact opposite of analysis. It is putting elements and parts together again to make a new integral whole, system, unit or a structure that has not existed before. These kinds of abilities imply that students should have some past experience in building parts together and forming relations between these parts by using new materials (Al-Fatlawi, 2003). According to (Bloom et al, 1985) this level focuses on the creative behavior but within the required theoretical framework.

6) Evaluation: Evaluation is the last and most sophisticated cognitive level in the taxonomy because it involves all the previous cognitive levels. It reveals a student's ability to make a judgment about a certain purpose that concerns the value of the content, ideas, solutions or techniques according to certain criteria that might be internal which explores the sequence of the ideas, or external such as in comparing one content to another in relation to their levels (Al-Darab'eh, 2006) .However, it should be kept in mind that the abilities in the six levels of Bloom's Taxonomy are not taught independently or individually. Rather, teachers should design a program that develops them all in a simultaneous manner and provide opportunities that help students improve their intellectual skills according to their mental and developmental level (Habib Allah, 2000).

In order to evaluate the scientific achievement in the USA, Ulic and Julia (2000) investigated questions included in the national exams in 48 states. Results showed that those tests examined a wide variety of skills and that in 37 states, students had to do performance tests. Consequently, some American states such as Kentucky expressed a significant scientific development. Sulaiman (2000) compared assessment questions in history textbooks in a Syrian school to Sander's Taxonomy (1966). He found that most questions tested lower levels of cognition and that objective questions were almost excluded while the greatest focus was on open and closed written question items.

AL-Dasoqi (2000) examined the extent to which the content of the Arabic language textbook was taught to the third preparatory students and which meets the goals assigned for that curriculum. His study also aimed at analyzing and evaluating assessment questions in that textbook according to cognitive, affective and psychomotor domains in Bloom's Taxonomy and detecting the use of objective and written questions. To achieve the purposes of his study, the researcher prepared a content analysis list and developed two questionnaires that examined these aims from the points of view of both teachers and students. Results revealed that five out of the six items evaluating assessment questions received higher values. Other results indicated that those questions ranked better when they are related to content, include both objective and comprehension formats, clear and consider understanding and reflect all the domains in Bloom's Taxonomy.

AL-Jallad (2001) analyzed questions which were introduced in the Islamic Education textbooks and were taught in Jordan for grades eight, nine, and ten to explore the degree to which written or objective questions were used and what sort of items objective questions included. For these purposes, the researcher designed the analysis instrument and based his work on the cognitive, affective and psychomotor criteria in Bloom, Krathol and Kippler. In addition to the extensive use of written questions, analysis showed that items measuring synthesis skills were completely ignored and that most of the remaining questions focused on lower thinking skills.

AL-Darab'eh (2006) studied the extent to which comprehension questions in "Our Arabic Language” textbook for grade four in Jordan focus on developing thinking skills in learners in reference to Bloom. The sample of her study included 198 questions, the instrument of her study was a list of the criteria presented in Bloom in order to measure the questions. Statistics revealed that $80 \%$ of those questions focused on lower cognitive levels (knowledge and understanding) while only $18 \%$ tested all other cognitive skills and processes. Both Kariluz and Vicente held a study in 2010 aimed at analyzing three of the most widespread public school chemistry textbooks in the USA where the mentioned questions and problems at the end of the units and chapters were also analyzed.

The results referred that most of Bloom's Taxonomy commonly used domain levels in these books are the application 
level then the analysis level and the most common of science is the chemical operations, inference and forecasting estimations, and rarely are there questions which require translation, comparison, linking data, formulating hypotheses and sentencing because all these levels are high, comparing them with those reflecting these questions.

Kahaveci held a study in 2010 which aimed at holding quantitative analysis for the textbooks of both chemistry and science in the Turkish schools according to the gender equality, level of questions, vocabulary connotations of the science subject, and the comparison level. All words, pictures, models and questions were analyzed according to the knowledge level. One of its results was that there was nonconformity for the questions and the knowledge levels. The study recommended more attention to these questions in the analyzed science textbooks.

But the study held by both AL-Ayassreh and Uttom in 2011 aimed at analyzing the mentioned questions in the developed textbooks for both first and second basic classes in Jordan according to the questions of the school textbooks and the fields of learning and its levels. The results were that the percentage of questions in the low levels was the highest and concentration was higher on, mainly, the level of understanding while it was less in the higher levels, mainly, in the understanding level.

In another study held by Abu Jahjouh in 2013, it aimed at limiting the percentages of mental representation of the domain levels, and limiting the percentages of the representation of the written and multiple choice questions of the chemistry textbook in the 12th grade class in Palestine.The researcher followed the style of the content analysis and the results indicated the percentage of the questions of the mentioned textbook concentrated, mainly, on the application level then the level of remembrance then the understanding level while it was obviously less in the other levels. The percentage of the multiple choice questions became less than that one of the written questions which was $22 \%$, while it was $78 \%$ in the comprehension questions.

Studies, reviewed earlier and this new study, have many aspects in common. For example, they all base their research plan and application in analyzing and evaluating questions in reference to Bloom. Some studies such as AL-Dasoqi 2000 and AL-Darab'eh 2006 provided useful resources for this researcher to develop the instrument of his study, and guidance in the procedures and in building the questions of his study in order to achieve the purpose of evaluating the assigned Arabic language textbook. All these studies address the importance of measuring the different cognitive skills and levels particularly those of analysis, synthesis and evaluation. These studies used analysis and evaluation formats and questionnaires administered by experts and teachers in order to evaluate textbooks and the assessment questions they include.

In addition to investigating cognitive domain, some previous studies explored the affective and psychomotor abilities like in AL-Dasoqi 2000 and Al-Jallad in 200. A number of previous studies including Al-Jallad in 2001, aimed at studying the types of questions included in certain textbooks and the types of objective items they included. He also used other affective and psychomotor taxonomies in addition to Bloom. Sanders, 1966, made the bases of a question analysis which Sulaiman, 2000, used in his study.

This study was different from a number of previous studies in terms of the nature of the content. Some of these studies addressed the content of non Arabic language curricula as the studies of (Kahveci, 2010; Kariluz, Vicente, 2010; Abu Jahjouh, 2011) analyzing of content and questions in chemistry and science curricula was done. In the field of Arabic Language, the study of Darab'ah in 2006 dealt with the comprehension questions published in the Arabic textbook of the fourth grade in Jordan and its impact on the development of thinking among the students according to Bloom's cognitive levels.

One of the previous studies dealt also with the analysis of two sides which are the content and the questions. The questions were classified, according to Bloom's classification, into three classes which are cognitive, emotional and self - kinesthetic, that's the study of (Dassoki, 2000). The present study focuses on questions included in an Arabic language textbook for grade eight to investigate the degree to which these questions represent the six levels of the cognitive domain in Bloom (remembering, understanding and comprehension, application, analysis, synthesis and evaluation). This study is characterized by adopting certain criteria that decide the percentages of distributing these questions within the six levels in Bloom so that a decision can be made about their quality.

\section{Methodology and Procedures}

\subsection{The Population and Sample of the Study}

The research sample consists of all the mentioned questions in the eighth grade communication skills textbook in Jordan in both the first and second semesters. This book contains lessons in listing, speaking, reading, and writing skills. It's taught in all schools in the Hashemite kingdom of Jordan with a decree no. 40/2005 in the Ministry of 
Education 4th/5/2005 it has been decreed from the academic year 2005/2006 till now. This book was written by four specialists in the writing of Arabic Language books and textbooks. The writers are a professor, associate professor, and two experienced teachers who taught Arabic Language in the Jordanian public schools. The research sample consists of all the questions of all the Subjects and Lessons in the mentioned textbook which is estimated at 520 questions of which 258 questions are in the first semester and the others estimated at 262 questions are in the second semester.

\subsection{Methodology}

The researcher followed the descriptive analytical approach because the study aims at making qualitative estimations and because the main concern of this study is to analyze questions included in the content of the above mentioned textbook. The procedures carried out by the researcher in this field will be clarified later.

\subsection{The Instruments of the Study}

The research tools were analysis Card consists of the main title for each unit of the mentioned textbook and the Six cognitive levels (remembering, understanding and comprehension, application, analysis, structure, and evaluation) in Bloom's classification. These categories were adopted for analyzing the questions of each unit of the mentioned textbook.

A list of standard percentages of the assessment questions distributions according to these six levels in Bloom was prepared and conducted by the researcher.

\subsection{Procedures}

The researcher followed these steps:

1) Designing an analysis card for the questions of the mentioned textbook which is the first former tool of the tools of studying. Each question of the textbook will be printed according to its six cognitive levels according to Bloom's classification. The Card should be displayed on experienced arbitrators who are specialized in education and linguistics to make sure that the card is right. Any amendments should be done according to the arbitrators such as adding titles of the main textbook units mentioned in the mentioned book and correcting any linguistic or printing mistakes.

2) Analyzing of the textbook questions (each one separately) and putting them in the analysis card according to their levels and getting the percentage of each level of the six cognitive levels. Outsourcing of two experienced linguistic and educational analysts to be sure of the accuracy of the analysis. These two analysts were asked to re- analyze the questions and putting them in the analysis card designed before according to their levels.

3) Preparing a list of the percentages of the standard levels in the questions of the mentioned book according to Bloom's Taxonomy in the cognitive domain and by referring to some sources, including the book " Outlines of Arabic Language curriculum " in the basic education in Jordan and through the researcher's experience in this field, a percentage that would prefer to take into account the questions of the book levels.

4) Checking this list by experts and scholars who have varied educational and scientific qualifications from different domains in order to vivify them

5) Collecting the proposals of the results of the opinions of the arbitrators and extracting the averages for these ratios in each level and bringing out the list of the normative ratios of the question levels of the mentioned book in its final image.

6) Comparing the percentages which appeared through the results of analyzing the questions of the mentioned book according to the analysis card designed before with the normative ratios which were limited and adopted after being shown by the specialized researchers and educators, the percentages which should be preferably taken into consideration in the levels of the questions of the book.

7) Stating and explaining these results to suggest necessary recommendations.

\subsection{Analysis Steps and Procedures}

\subsubsection{Categories and Units of the Analysis}

The researcher used Bloom's Taxonomy of knowledge as the main category of analysis and its six levels (remembering, understanding and comprehension, application, analysis, structure, and evaluation) were assigned as the minor units for the same purpose. Every question item, wherever it a appears in the targeted textbook was treated as a unit of analysis. 


\subsubsection{Analysis Steps}

1) The researcher reads the questions thoroughly and carefully as introduced in the Arabic Language textbook "Communication Skills" for grade eight.

2) The researcher then analyzes the questions of the mentioned book by putting each question according to its level of the six levels (remembering, understanding and comprehension, application, analysis, structure, and evaluation) in the suitable square and taking also into account the designed analysis card so as to limit the percentage of questions in each level later and to compare it with the normative ratios percentage which should also be taken into consideration in the level of the questions in the mentioned book.

3) Two well-experienced analysts of curriculum and teaching help the researcher to confirm the accuracy of analysis. These two analysts analyze the questions of the mentioned book in one session then the researcher decides to apply reliability coefficient according to the law of Holsta equation (Tu'amah, 2004).

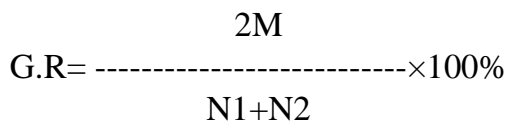

The following Symbols mean:

G. R means: Coefficient of agreement between the analysis of the main researcher and the analysis of the researcher.

3M means: The number of times of the agreement between the main researcher and the other researchers.

N1 means: The number of times of the agreement.

N2 means: The number of times of no agreement.

The overall reliability coefficient based on the analysis was (91.6) which makes a sufficient value for the purposes of this study.

\subsection{Statistical Treatment}

The statistical procedures used in this study included using percentages, means and differences between percentages to introduce the results in a quantitative description.

\section{Results and Discussion}

8.1 Results and Discussion of the First Question: What are the percentages of distributing the questions introduced in Arabic Language textbook "Communication Skills" within each level of knowledge in Bloom's Taxonomy (remembering, understanding and comprehension, application, analysis, synthesis, and evaluation)?

To answer this question, the researcher calculated the percentages of the distribution of these questions within each level of the Taxonomy. Table 1 shows the results of these calculations.

Table 1. Percentage of the Questions Included in the Textbook According to Bloom's Taxonomy

\begin{tabular}{lll}
\hline Level & Number of Questions & Percentage \\
\hline Remembering & 165 & $\% 31.73$ \\
Comprehension & 204 & $\% 39.23$ \\
Application & 48 & $\% 9.23$ \\
Analysis & 29 & $\% 5.57$ \\
Synthesis & 58 & $\% 11.15$ \\
Evaluation & 16 & $\% 3.07$ \\
Total & 520 & $\% 100$ \\
\hline
\end{tabular}

The numbers in Table one show an unbalanced distribution of the questions within the six levels. The total number of the questions was 520. The questions in the remembering level were 165 with a percentage of $31.73 \%$, questions measuring understanding and comprehension ranked first with a total of 204 and percentage that equals $39.23 \%$, the 48 questions measuring application represent a percentage of $9.23 \%, 29$ questions assess analysis with a percentage of $5.57 \%$, within the level of synthesis, the percentage was $11.15 \%$ representing a total of 58 questions, and the 16 questions assessing evaluation ranked the last with a percentage of only 3.07.

The figures in table (1) clearly reveal that questions included in grade eight Arabic language textbook focus on the first two levels of the taxonomy (remembering and understanding) with the percentages of $31.73 \%$ and $39.23 \%$ 
respectively. This result supports results introduced AL-Darab'eh (2006) who investigated Arabic language textbooks.

This disparity in the percentage of questions in each level is considered normal. What is required is not to make the percentages equal but also not to concentrate on one level and to neglect the other levels, or to decrease the percentages of questions obviously.

Bloom and his colleagues said both remembering and comprehension levels are the foundation and broad - based access to other higher levels, where each level is a foundation and starting point for subsequent levels that follow it.

Percentages representing the higher levels of thinking, application, analysis, synthesis and evaluation were significantly low $(923 \%, 5.57 \%, 11.15 \%$, and 3.07$)$ in comparison to the first two levels in the Taxonomy.

Increasing of the percentage of questions at the level of remembering is due to the attention which the authors of the book may give to the process of retrieval of the scientific knowledge which the student learned before, and concentrating on remembering its facts, idioms, principles, and generalizations without using it or to issue any rules related to it.

But concentrating on understanding and comprehension may appear as a result as what was available in the book related to the learning content and which the learner is required to express all the notions that the studies in a special style which is different from what he learned provided that both accuracy and clarity are available.

This level may also be, increasingly, used in the questions used by the teachers which are related to the reading of comprehension while reading "a piece of reading" with questions around it.

The percentage of questions at the other levels (higher) which are the application, analysis, synthesis and evaluation are low compared with the increase in the first and second levels which reach 9.23\% at the application level, 5.57\% at the analysis level, $11.15 \%$ at the synthesis level and $3.07 \%$ at the evaluation level with the existence of differences in these ratios.

The reason may be due to the fact that the questions of the highest levels of knowledge require the fabricators more time, effort, expertise and questions than remembering or understanding and thus the reason may be the difficulty of establishing these questions and the evidence was expressed by Bloom by saying that the questions require new situations as well as the principles which need to be analyzed, evaluated and installed. All these need less specific answers of remembering and understanding because of the difficulty of the questions (Bloom et al, 1985).

The reason may be due to the perception of the authors of the Arabic language and their belief that this article which we need to learn and teach its concepts may require the other skills of thinking to focus on reciting and retrieval.

The questions in the upper levels of the learner do not require definition and clarification of the concept but to discover it, and they also require using the ideas more than remembering them, and this needs knowledge of the skills of analysis, classification, conclusion, generalizations and evaluation of the knowledge.

It can be noticed that there is a difference in the proportion of the three levels of the recent questions (analysis, synthesis, and evaluation) in favors of the installation level and the reason may due to the presence of writing lessons which are intended to be expressive focusing on this skill. The questions asking the students to compose subjects or expressive texts were repeatedly mentioned. The student may get help by collecting the ideas which are helpful to write a subject.

8.2 Results and Discussion of the Second Question: What are the standard percentages which the experts suggest for distributing assessment questions in this textbook in each cognitive level in the Taxonomy?

In answering this question, the researcher referred to the guidelines book of Arabic Language curriculum in Jordan, consulted some specialists, and used his own experience in the field. The suggested percentages were identified in reference to Bloom's Taxonomy. Those percentages were organized in a questionnaire that was judged by professors, researchers, associated professors and assistant professors in the field of instruction and curricula while other specialists work in supervision in addition to some Arabic language teachers. The means of these percentages were calculated and introduced in a final version listed in table (2). 
Table 2. Standard Percentages of the Questions Included in the Textbook According to Bloom's Taxonomy

\begin{tabular}{lllllll}
\hline The Standard Percentages of the levels of Aims of the Knowledge Domain & Total \\
\cline { 1 - 5 } Remembering & $\begin{array}{l}\text { Comprehension } \\
\text { and } \\
\text { Understanding }\end{array}$ & Application & Analysis & Synthesis & Evaluation & Percentages \\
\hline$\% 25$ & $\% 21$ & $\% 19$ & $\% 15$ & $\% 12$ & $8 \%$ & $100 \%$ \\
\hline
\end{tabular}

The above table clearly shows the standard percentages going in a regressive sequence that starts with remembering $25 \%$ and ends with the percentage of $8 \%$ representing evaluation. It is worth noting that the differences between the percentages in the table do not significantly vary and almost have the same small equal ranges.

The standard percentages in table (2) look correct and logical and results can be considered because the lower cognitive levels of remembering and understanding still occupy the highest percentages. Considering the fact that this study is concerned with a textbook taught to students in the basic level, it is logical that there is a greater focus on basic cognitive skills such as remembering because it is still time to build for the coming stages. Students in grade eight are at the end of a basic schooling stage where cognitive processes become more sophisticated and when time is due to prepare them for an abstract cognition, creative and critical thinking.

This result also supports the theory by Bloom which suggests the gradual and balanced transition from one level to the other. This transitional movement should meet the growth requirements of each level and eliminate any gaps during learning to guarantee sustainable and stable cognitive structure.

Reaching to this result may be important because it was easy to reach to the normative ratios of the level of questions through this result preferably questions on the book of Arabic for the eighth basic class in Jordan according to the proposals and opinions of the experts, researchers, teachers, educators and academics. Here, it could be ruled on the suitability of the level of questions in the mentioned book with the educational level and the school stage of the eighth basic class.

This subject could help us to know the validity of the questions in this book and to rule on its educational value for the learners and to know also its quality and what is weak so as to avoid and what is strong so as to strengthen more.

8.3 Results and Discussion of the Third Question: What is the level of agreement between the results of analysis of these questions that was done by the researcher and the standard percentages suggested by the experts?

To answer this question, the researcher compared the percentages of the questions included in the textbook within the different levels in Bloom to the standard percentages which the experts and specialists suggested. Table (3) introduces these results:

Table 3. Level of Agreement between the Results of Analyzing the Questions According to Bloom's Taxonomy Included in the Textbook and between the Standard Percentages

\begin{tabular}{lll}
\hline The Level & $\begin{array}{l}\text { Percentages of the questions of } \\
\text { the book }\end{array}$ & $\begin{array}{l}\text { The } \\
\text { Percentages }\end{array}$ \\
\hline Remembering & $\% 31.73$ & $\% 25$ \\
Comprehension and Understanding & $\% 39.23$ & $\% 21$ \\
Application & $\% 9.23$ & $\% 19$ \\
Analysis & $\% 5.57$ & $\% 15$ \\
Synthesis & $\% 11.15$ & $\% 12$ \\
Evaluation & $\% 3.07$ & $\% 8$ \\
Total of Percentages & $\% 100$ & $\% 100$ \\
\hline
\end{tabular}

Numbers in Table three reveal a significant disagreement between the percentages of the analysis done by the researcher and the standard percentages which the experts suggested as ideal to be included in five levels in Bloom. For example, in the remembering level the percentage calculated by the researcher was $31.73 \%$ while the experts suggested 25\% for the same level, comprehension and understanding represented the percentage of 39.23\% in the textbook and $21 \%$ as a standard percentage, and the standard percentage for application was as high as $19 \%$ whereas the textbook represented questions in this level with a percentage of only 9.23. The same applies to analysis that had the actual percentage of only 5.57\% in the textbook while the experts suggested that it is worth the percentage of $15 \%$ and the evaluation of $3.07 \%$ in the textbook and a suggested standard percentage that reaches $8 \%$. 
It is, clearly, evident that synthesis is the area where the results given by the researcher and the suggested standard percentages respectively match with the percentages of $11.15 \%$ and $12 \%$. However, Table (3) still introduces high percentages for remembering and "understanding and comprehension" in both results of the analysis made by the researcher and the standard percentages suggested by the other experts. This may be due to the fact that "Communication Skills" textbook includes a considerable quantity of lessons and topics that require these cognitive abilities at this level of schooling.

This may also be related to a belief held by curricula authors that at this stage of learning, students need these two skills of cognition to build the platform for future creative learning. In other words, students cannot master the higher level skills such as application, analysis, synthesis or evaluation unless they have the strong cognitive background which is necessary to do that job.

Classical principles of learning psychology suggest another interpretation for these outcomes. For instance, Herbert emphasized the fact that individuals have a variety of distinctive intellectual abilities such as recalling, focusing attention and using imagination and that each one of these abilities could be taught independently. Moreover, theorists believe that different subjects have specific characteristics that might be categorized under these abilities. Arabic language is a very good example of these subjects: it is rich in facts, notions and concepts whose learning requires reciting and recalling. This is supported by the principles of behavioral theory in learning which states that learning is actually about producing what has been learnt.

Despite all these justifications, "Communication Skills" textbook still exaggerates focusing on the first two cognitive skills more than other levels particularly the two skills of analysis and evaluation that had the lowest percentages of representation. It is worth noting here that many topics included in this textbook require that the learner should analyze them first so that he can comprehend them well and later apply their content in novel situations which will, in turn, facilitate evaluating them.

Authors realize that writing a topic is the skill where synthesis mostly resides because it is the area where learners employ their understanding of all the aspects of the language to "synthesize" the final output.

This characteristic of writing may explain why questions measuring synthesis were represented in almost equal percentages in all the calculations of the percentages.

\section{Summary of the Results of the Study (Conclusion)}

1) The result related to question No. 1: The result of the first question shows how the questions of the Arabic textbook " Communication Skills " for the eighth basic class in Jordan concentrate on both the first and second levels which are the remembrance and comprehension levels according to Bloom's classification mainly comprehension and understanding while the percentage of the questions in the other levels (application, analysis, structure, and evaluation) are low. Structure level got the highest percentage.

2) 2-The result related to the second question: The result of the second question in dictated to the gradient presence in the percentage of the standard questions for the levels of the questions in the textbook from the highest to the lowest.

3) The highest percentage was in the remembrance level then to go down gradually in the other levels. The lowest percentage reaches in the evaluation level without any big differences between each level. 3-The result related to the third question: The result related to the third question referred that there was no consensus between the percentages of the levels of the mentioned textbook and the percentages of the suggested standard questions which may be from the levels of remembrance, comprehension and understanding, application, analysis and evaluation while there was rapprochement between the percentage of the textbook in the structure level with the standard percentage for the same level.

\section{Suggestions and Recommendations}

In the light of the results of this study, the researcher recommends the following:

1) Increasing attention in learning the higher thinking skills in the mentioned book particularly in the levels of application because of the low percentage of the questions mentioned in these levels comparing them in the low levels.

2) Introducing questions that consider the gradual and balanced development of both the learner and the content and go in harmony with each other. 
3) Doing more studies related to the analyzing of the questions of Arabic book in all the school stages.

4) Evaluating the exams prepared by the ministry of education to check the degree to which they represent the levels in Bloom's Taxonomy.

5) Conducting other similar studies on textbooks of other courses that have not been analyzed before for the same purposes.

6) More studies should be carried out to evaluate the extent to which they represent the affective and psychomotor domains in Bloom.

\section{References}

Abdel Razaq, S, A. (2003). Developing skills of wording written questions and preparing examination for all levels of education. Cairo Dar for Books: Egypt.

Abu Jahjouh, Y. (2013). Analysis of the questions of the chemistry book for the 12th class in Palestine. Al Najah university magazine for the researches (human science), 27(4), 847-886.

AL-Adwan, Z., \& Al-Hawamdeh, M. (2008).Teaching design between theory and practice (1st edition). Jadara for college book: Amman - Jordan. Modern world of books: Irbid - Jordan.

Al-Ayassreh, A., \& Uttom, K. (2011). Analysis of the developed books for the IST \& 2nd basic classes in Jordan according to the types of questions \& the fields of science \& their levels. Um Al Qurra university magazine of the Psychological educational science, 3(1), 304-344.

AL-Darab'eh, I, T. (2006). Analyzing comprehension question in Arabic textbook for elementary school grade four in Jordan in the light of Bloom levels of knowledge, unpublished MA thesis, faculty of graduate studies, Amman Arabic University.

AL-Dasoqi, W. (2000). Assessment of Arabic Language Course for third Graders in Middle School in Qatar, M4 thesis, Faculty of Graduate Studies, AL soudan University.

AL-Fatlawi, S, M. (2003). An introduction to teaching (1st edition). AlShoroqe Dar for publishing and distribution. Amman- Jordan.

Al-Haj Isaa, A, H. (1995). The Extent to Which the Questions in the Arabic Language Textbooks of the Fifth and Sixth Basic Grades Concentrate on the Student's Thinking Skills, Degree master (unPublished), The university of Jordan, Amman, Jordan.

AL-Hasan, H., \& Al Qaid, S. (1999). Planning and Developing Curricula (2nd edition). Dar Safa'a for Publishing: Amman, Jordan.

AL-Husari, A. (1995). Teaching Methods for Diploma Students of Educational Qualification. Publications of Demascus university.

AL-Hwaimel, O. (2003). The extent of emphasis played by the question of Arabic language textbook on developing analytical thinking for 11th grade literary stream students, unpublished MA thesis. Amman Arab university, Amman-Jordan.

AL-Jallad, M. (2001). Analyzing assessment questions involved in Islamic education Materials for eighth, nineth and tenth Grades in Jordan. Alyarmouk rasearches, 7, 38- 83.

AL-Khawaldeh, N., \& Eid, I. (2003). Methods of Teashing Islamic Education with its Practical applications (2nd Edition). Alfalah Limrary: Kuwait and UAE, Dar Janin: Amman.

AL-Maliki, A. (2005). Islamic education skills (1st edition). Ministry of Awqaf and Islamic Affairs ,Qatar.

AL-Marzouq, S. (1997). Analytical and assessment study of Arabic textbook material questions for middle school student in Bahrain. MA theses in education submitted in Bahrain until the end of 1998, 1,

AL-Qalla, F. (2000). Origins of teaching, faculty of education. Damascus university.

AL-Rawadieh, S. (2000). Comparing Cognitive Levels of Questions of Social Studies Textbooks for $12^{\text {th }}$ Grade high Secondary School Students - Literary Stream in Jordan during the Period (1976 - 1996) and (1996 - 1999) (Analytical Study). Mu'tah for Researches and Studies, F 15, N 3.

AL-Samook, S., \& AL-shammari, H. (2009). School Curricula between tradition and modernization (1st edition). Alwaraq Dar for publishing and distribution: Amman-Jordan. 
AL-Shammari, H., \& AL-samouk, S. (2005). Islamic education learning assessment (1st Edition.). Amman: Wa'el Dar.

AL-Zahrani, A. (2003). Creative thinking from Islamic education Prespective. Education, Egypt, Page (197-214).

AL-Zubi, M. et al. (2007). Referential book in Preparing Curricula and School material authorship and Learning resources (1st edition). Curricula and Textbooks administration, Ministry of Education, Jordan.

Bloom B. (1964). Taxonomy of Education Objectives Handbook 1, Cognitive Domain. New York: David Mckay Co, Inc, Wixson.

Bloom, B, et al. (1985). The system of classifying the educational targets, C1 (knowledge field), Translated by: Mohammed Mahmmod \& Sadeq Odeh, Jeddeh: Dar Al shorooq.

Cooper, J. M. (1999). Classroom Teaching Skills. University of Virginin.

Darwazeh, A, M. (2005). Educational questions and School assessment (1st Edition). Dar ALshrooq for Publishing and Distribution: Amman, Jordan.

Darwazeh, A, M. (2006). Curricula and its Evaluation Criterion. Nablis.

Habib Allah, M. (2000). Basics of Reading and Comprehension Through theory and Practice - an Learning. Dar Amar for Publishing: Amman, Jordan.

Hamadin, F. (2003). Analyzing Assessment Questions Included in Geographic Materials for Secondary Level in Oman in the Light of Educational Purposes. Educational Magazine, 17(68), 57-95.

Jasim, S. (2000). Evaluation of Material questions involved in Chemistry course taught for Scientific Stream secondary Level- Grade Four in Kuwait in the Light of the Purposes of Teaching Chemistry. Educational Magazine, 14, 31-36.

Kahveci, A. (2010). Quantitative Analysis of Science and Chemistry textbooks for Indicators of Reform: A complementary perspective. International Journal of Science Education, 32(11), 1495-1519.

Kariluz, D., \& Vicente, T. (2010). Classifying end of chapter questions and problems for selected general chemistry textbooks used in the United States. Journal of Chemical Education, 87(1), 97-101.

Lippse, R., \& Freeman, H. (2004). Evaluation; A- Systematic Approach. London: Sage Publication.

Marie, T., \& Al Heilah, M. (2000). Modern Curricula with its Concepts, Elements basics and Processes (1st edition). Almaserah Dar for Publishing and Distribution, Amman - Jordan.

Marie, T., \& Alheilah, M. (2003). Modern educational Curricula. Almaserah Dar for Publishing and Distribution, Amman - Jordan.

Migdadi, M, F. (1992). Comparing comprehension abilities of 8th grade strong active pupils and weak passive and ones after performing both silent and loud reading: Empirical study. Yarmouk researches, human sciences and education series, 8(1), 129-150.

Ministry of Education. (2000). Adjust the quality of education of basic levels for the academic Years (1999-2000). Amman-Jordan.

Ministry of Education. (2003). Statistical report: National tests to adjust quality education and diagnosis for academic Years (2000-2003). Amman-Jordan.

Qatami, U., Abu Jaber, M., \& Qatami, N. (2002). Teaching design (2nd edition). Alfiqir Dar for publishing and distribution: Amman-Jordan.

Shabattat, M., Khattaybeh, A., \& Hamadeen, F. (2003). Strategies of asking questions by the teachers of science, Islamic education, and Social studies in Oman Sultanate. Magazine of studies in Curricula \& teaching methods, (87), 169-201.

Skaker, F. (1995). Effectiveness of detective thought methods in teaching environmental education. PHO thesis, Damascus university.

Sulaiman, J. (2000). Analytical study for material questions included in history textbook in basic school republic of Syria. Damascus university Magazine for Art and human sciences, 16, N3.

Sweedan, K. (2009). Analytical and assessment study for physiographic text book material questions for 11th graders in schools of republic of Syria according to Bloom classification in field of knowledge. Damascus university 
Magazine, 25(2), 551-575.

Touq, N., Qatami, Y., \& Adas, A. (2003). Basics of Phycological Education Science. Intellect Dar For Publishing: Amman, Jordan.

Tu'aimah, R. (2004). Analysis of content in human science: its concept, aims and its uses (3rd edition). Dar Al fiker: Cairo.

Ulik, R., \& Julia. (2000). Insights: SEDL. The Southwest Educational Development Laboratory. 